\title{
Towards the Provision of Assistance for Very Small Entities in Deploying Software Lifecycle Standards
}

\author{
Rory V. O'Connor \\ Lero, Irish Software Engineering Research Centre \\ Dublin City University \\ Ireland \\ rory.oconnor@lero.ie
}

\author{
Claude Y. Laporte \\ Department of Software and IT Engineering \\ École de technologie supérieure \\ Montréal, Canada \\ claude.y.laporte@etsmtl.ca
}

\begin{abstract}
This paper outlines the recent development of a series of detailed guidelines known as "Deployment Packages" (DPs) for use with the emerging ISO/IEC 29110 software process lifecycle standard for Very Small Entities (VSEs). Such DPs are intended to provide detailed guidelines and explanation presenting in more detail the processes defined in the ISO/IEC 29110 profiles. This paper will also outline a pilot project initiative currently underway to evaluate these Deployment Packages and assist very small companies in understanding and exploring the potential usage of an international software process development standard.
\end{abstract}

\section{Keywords}

ISO/IEC 29110, Lifecycle standards, VSE

\section{INTRODUCTION}

Industry recognizes that very small companies that develop software systems are very important to the economy. For such companies failure to deliver on time, within budget a quality product threatens the competitiveness of both organizations. One way to mitigate these risks is by having all suppliers of a product chain to put in place recognized engineering practices. Many international standards and models like ISO/IEC12207 or CMMI have been developed to capture proven engineering practices. However, these standards were not designed for very small companies and are consequently difficult to apply in such settings.

This section discuses the concepts of small and very small companies and issues surrounding the adoption of software process standards by such companies, prior to an introduction to ISO/IEC 29110 and the development of a series of Deployment Packages to support the implementation of ISO/IEV 29110 process practices.

\subsection{Very Small Entities (VSEs)}

The definition of "Small" and "Very Small" Entities is challengingly ambiguous, as there is no commonly accepted definition of the terms. For example, the participants of the 1995 Capability Maturity Model (CMM) tailoring workshop [1] could not even agree on what "small" really meant. Subsequently in 1998 SEPG conference panel on the CMM and small projects small was defined as "3-4 months in duration with 5 or fewer staff'. Johnson and Brodman [2] define a small organization as "fewer than 50 software developers and a small project as fewer than 20 software developers".
To take a legalistic perspective the European Commission [3] defines three levels of small to medium-sized enterprise (SME) as being: Small to medium - "employ fewer than 250 persons and which have an annual turnover not exceeding 50 million Euro, and/or an annual balance sheet total not exceeding 43 million Euro"; Small - "which employ fewer than 50 persons, and whose annual turnover and/or annual balance sheet total does not exceed 10 million Euro" and Micro - "which employ fewer than 10 persons and whose annual turnover does not exceed 2 million euro".

To better understand the dichotomy between the definitions above it is necessary to examine the size of software companies operating in the market today. In Europe, for instance, $85 \%$ of the Information Technology (IT) sector's companies have 1 to 10 employees. In the context of indigenous Irish software firms $1.9 \%$ (10 companies), out of a total of 630 employed more than 100 people whilst $61 \%$ of the total employed 10 or fewer, with the average size of indigenous Irish software firms being about 16 employees [4]. In Canada, the Montreal area was surveyed, it was found that $78 \%$ of software development enterprises have less than 25 employees and 50\% have fewer than 10 employees [5]. In Brazil, small IT companies (less than 50 employees) represent about $70 \%$ of the total number of companies [6].

The term "very small entity" had been defined by the ISO/IEC JTC1/SC7 Working Group (WG) 24 and subsequently adopted for use in the emerging ISO/IEC 29110 software process lifecycle standard [7], as being "an entity (enterprise, organization, department or project) having up to 25 people”.

\subsection{VSE and Standards}

In a time when software quality is a key to competitive advantage, the use of ISO/IEC systems and software engineering standards remains limited to a few of the most popular ones. Research shows that VSEs can find it difficult to relate ISO/IEC standards to their business needs and to justify the application of the standards to their business practices. Most of these VSEs can't afford the resources - in number of employees, cost, and time - or see a net benefit in establishing software life-cycle processes. There is sometimes a disconnect between the short-term vision of the company, looking at what will keep it in business for another six months or so, and the long-term benefits of gradually improving the ways the company can manage its software development and maintenance. A primary reason cited by many small software companies for this lack of adoption of such ISO standards, is the perception that they have been developed for large multi-national software companies and not with the small organisation in mind [4]. Subsequently, VSEs have no or very limited ways to be recognized as enterprises that produce quality 
11th International Conference on Product Focused Software Development and Process Improvement (Profes2010), Hosted by LERO, Ireland, June 21-23, 2010.

software systems in their domain and may therefore be cut off from some economic activities.

Accordingly there is a need to help such organizations understand and use the concepts, processes and practices proposed in the ISO/IEC JTC1/SC7's international software engineering standards.

\section{ISO/IEC 29110}

From the VSE perspective, there are many potential benefits of using standards which are specifically designed to address there needs including good internal software management processes, greater customer confidence and satisfaction, greater software product quality, increased sponsorship for process improvement and decreased development risk. These benefits might also help the VSE in increasing competitiveness and market share.

The ISO/IEC 29110 standard "Lifecycle profiles for Very Small Entities" [7] is aimed at addressing the issues identified above and addresses the specific needs of VSEs [8].

The approach [8] used to develop ISO/IEC 29110 started with the pre-existing international standard ISO/IEC 12207 [9] dedicated to software process lifecycles. The overall approach consisted of three steps: (1) Selecting ISO/IEC 12207 process subset applicable to VSEs of less than 10 employees; (2) Tailor the subset to fit VSE needs; and (3) Develop guidelines for VSEs.

At the core of this standard is a Management and Engineering Guides (ISO/IEC 29110-5) [10] focusing on Project Management and Software Implementation and an Assessment Guide (ISO/IEC 29110-3) [11].

It is worth noting that as with all proposed ISO standards, ISO/IEC 29110 is subject to the normal ISO review process. To date 1249 comments have been processed, over four meetings between 2008 and 2009.

\subsection{VSE Profiles}

ISO/IEC 29110 makes use of the concept of International Standardized Profile (ISP), where an ISP profiles promotes the integration of base standards by defining how to use a combination of base standards for a given function and environment. In addition to the selection of base standards, a choice is made of permitted options for each base standard and of suitable values for parameters left unspecified in the base standard.

The core characteristic of the entities targeted by ISO/IEC 29110 is size, however there are other aspects and characteristics of VSEs that may affect profile preparation or selection, such as: Business Models (commercial, contracting, in-house development, etc.); Situational factors (such as criticality, uncertainty environment, etc.); and Risk Levels. Creating one profile for each possible combination of values of the various dimensions introduced above would result in an unmanageable set of profiles. Accordingly VSE's profiles are grouped in such a way as to be applicable to more than one category. Table 1 illustrates a Profile Group which contains three profiles (labeled $\mathrm{A}, \mathrm{B}$ and $\mathrm{C}$ ) that are mapped to nine combinations of business models and situational factors.

Table 1. Allocating VSE characteristics to profile groups

Profile Situational Factors

\begin{tabular}{|c|c|c|c|}
\hline $\begin{array}{c}\text { Business } \\
\text { Models }\end{array}$ & Critical & $\begin{array}{c}\text { User } \\
\text { Uncertainty }\end{array}$ & $\begin{array}{c}\text { Environment } \\
\text { Change }\end{array}$ \\
\hline Contract & Profile A & Profile A & Profile A \\
\hline In-House & Profile C & Profile B & Profile A \\
\hline Commercial & Profile B & Profile A & Profile A \\
\hline
\end{tabular}

Profile Groups are a collection of profiles which are related either by composition of processes (i.e. activities, tasks), or by capability level, or both. The "Generic"" profile group has been defined [12] as applicable to a vast majority of VSEs that do not develop critical software and have typical situational factors. This profile group does not imply any specific application domain, however, it is envisaged that in the future new domain-specific sub-profiles may be developed in the future.

Table 2 illustrates this profile group as a collection of four profiles, providing a progressive approach to satisfying the requirements of profile group.

Table 2. Graduated profile group

\begin{tabular}{|l|l|l|l|}
\hline & \multicolumn{3}{|c|}{ Generic Profile Group } \\
\hline Entry & Basic & Intermediate & Advanced \\
\hline & & & \\
\hline & & & \\
\hline & & & \\
\hline & & & \\
\hline
\end{tabular}

To date the Basic Profile [10] has been specified, the purpose of which is to define a software development and project management guide for a subset of processes and outcomes appropriate for characteristics and needs of VSEs. The main reason to include project management is that VSEs core business is software development and their financial success depends on project profits. In order to benefit from the use of the Basic Profile, the VSE needs to comply with the following requirements:

- Project contract or agreement with Statement of Work

- The feasibility assessment was performed before the start of the project

- Human resources are assigned and trained

- A Project Manager Assigned

- Goods, Services and Infrastructures available

However, the issues of assistance to VSEs in understanding and adopting standards, as outlined in section 1 , must be addressed. To this end, some members of the ISO/IEC JTC1/SC7 WG 24 have produced a set of "Deployment Packages".

\section{DEPLOYMENT PACKAGES}

At the Moscow meeting of WG24, it was proposed, by Canada, to develop, as detailed guidelines, a series of deployment packages (DPs), to define guidelines explaining in more details the processes defined in the ISO/IEC 29110 profiles. The intention is that these guidelines will be published as ISO Technical Reports which should be freely accessible to VSEs. 
11th International Conference on Product Focused Software Development and Process Improvement (Profes2010), Hosted by LERO, Ireland, June 21-23, 2010.

A DP is a set of artifacts developed to facilitate the implementation of a set of practices, of the selected framework, in a VSE. A DP is not a process reference model (i.e. it is not prescriptive). The elements of a typical DP are: description of processes, activities, tasks, roles and products, template, checklist, example, reference and mapping to standards and models, and a list of tools. The mapping is only given as information to show that a deployment package has explicit links to standards, such as ISO/IEC 12207, or models, such as the CMMI for Development, hence by deploying and implementing the package, a VSE can see its concrete step to achieve or demonstrate coverage. Packages are designed such that a VSE can implement its content, without having to implement the complete framework at the same time. The table of content of a deployment package is illustrated in figure 1.

Figure 1. Table of Content of a deployment package.

1. Technical Description
Purpose of this document
Why this Topic is important
2. Definitions (Generic and Specific Definitions)
3. Relationships with ISO/IEC 29110
4. Detailed Description of Processes, Activities, Tasks, Steps,
Roles and Products
$\quad$ Role Description
$\quad$ Product Description
Artefact Description
5. Templates
6. Examples
7. Checklists
8. Tools
9. Reference to Other Standards and Models (ISO/IEC 12207,
ISO 9001, CMMI for Development)
10. References
11. Deployment Package Evaluation Form

Table 3 shows the DPs have been developed to date and the developing partner. These DPs are freely available from [13]:

\subsection{Implementation Guides}

In addition a series of "Implementation Guides" have been developed to help implement a specific process supported by a tool and are freely available from [13]. To date the following implementation guides have been developed:

- Version Control with CVS

- Version Control with SVN

- Project Management with GForge

- Issue tracking with GForge

- Software Process Improvement with OpenOffice Calc
Table 3. Graduated profile group

\begin{tabular}{|l|l|}
\hline \multicolumn{1}{|c|}{ Deployment Package title } & \multicolumn{1}{c|}{ Developed By } \\
\hline Requirement Analysis & Belgium, Canada \\
\hline Architecture and Detailed Design & Canada \\
\hline Construction and Unit Testing & Mexico \\
\hline Integration and Test & Columbia \\
\hline Verification and Validation & Canada \\
\hline Version Control & Thailand \\
\hline Project Management & Ireland \\
\hline Product Delivery & Canada, Thailand \\
\hline Self-Assessment & Finland \\
\hline
\end{tabular}

\section{Pilot Projects}

ISO/IEC JTC1/SC7 WG 24 are advocating the use of pilot projects as a mean to accelerate the adoption and utilization of ISO/IEC 29110 by VSEs. Pilot projects are an important mean of reducing risks and learning more about the organizational and technical issues associated with the deployment of new software engineering practices. A successful pilot project is also an effective means of building adoption of new practices by members of a VSE. Pilot projects are based on the ISO/IEC 29110-5 Management and Engineering Guide [10] and the deployment package(s). In particular these are aimed to collect, as a minimum, the following data:

- Effort and time to deploy by the VSE

- Usefulness for the VSE

- Verification of the understanding of the VSE

- Self-assessments data - A self-assessment at the beginning of the pilot and at the end of the pilot project DP

The members of WG24 requested a set of guidelines such that pilot projects are conducted similarly around the world. It was agreed to provide a Deployment Package to describe a process to conduct pilot projects. The purpose of this Deployment Package, developed by Canada and Uruguay, is to provide tailorable and usable guidelines and materials in order to select and conduct pilot projects in VSEs. The high-level tasks of this Deployment Package are:

- Assess the opportunity to conduct a pilot project,

- Plan the pilot project,

- $\quad$ Conduct the pilot project, and

- $\quad$ Evaluate the results of the pilot project.

To date a series of pilot projects have been completed in Canada utilizing some of the deployment packages developed. For example in Canada a pilot study has been conducted with an IT department with a staff of 4: 1 analyst and 3 developers, who were involved in the translation and implemented 3 DPs: Software Requirements, Version Control, Project Management. In Belgium a VSE of 25 people started with a process assessment phase aiming to identify strengths and weaknesses in development related processes. This company is now working on improvement 
11th International Conference on Product Focused Software Development and Process Improvement (Profes2010), Hosted by LERO, Ireland, June 21-23, 2010.

actions mainly based on the following Deployment Packages: Requirement Analysis, Version Control, Project Management. Finally in Ireland a VSE of 8 people are working on improving project management, tracking and control practices using the Project Management deployment package.

A further series of pilot projects are currently underway in Canada, Ireland, Belgium and France, with further pilot projects planned in the near future [14].

\section{Future Work}

As ISO/IEC 29110 is an emerging standard there is much work yet to be completed. The main remaining work item is to finalise the development of the remaining three profiles: (a) Entry - six person-months effort or start-up VSEs; (b) Intermediate Management of more than one project and (c) Advanced business management and portfolio management practices. In addition the development of additional Profile Groups for other domains such as: Critical software, game industry, scientific software development, etc.

So far, the means to accelerate the adoption of standards by VSEs has been described. A target audience, and an often forgotten one, in the area of software engineering standards comprise undergraduate and graduate students. At the Hyderabad meeting, the delegate from Canada proposed the establishment of an informal interest group about education. The main objective is to develop a set of courses for software undergraduate and graduate students such that students learn about the ISO standards for VSEs before they graduate. Work is already underway on the development of self-learning course modules to support DPs via a VSE Education Special Interest Group. To date four of the six courses have been developed and are freely available [15].

Finally, the technical development of plug-in modules (e.g. Eclipse) to support DPs is worthy of consideration.

\section{ACKNOWLEDGMENTS}

This work is supported, in part, by Science Foundation Ireland grant 03/CE2/I303_1 to Lero, the Irish Software Engineering Research Centre (www.lero.ie).

\section{REFERENCES}

[1] Ginsberg, M.; Quinn, L.; Process Tailoring and the Software Capability Maturity Model, Software Engineering Institute, CMU/SEI-94-TR-024, November 1995.

[2] Johnson, D.; Brodman, J.; Applying the CMM to Small Organizations and Small Projects, Proceedings of Software Engineering Process Group Conference, Chicago, 1998

[3] European Commission, 2005, The New SME Definition: User Guide and Model Declaration, available at: http://europa.eu.int/comm/enterprise/enterprise_policy/sme_ definition/sme_user_guide.pdf
[4] Coleman, G.; O'Connor, R.; Investigating Software Process in Practice: A Grounded Theory Perspective, Journal of Systems and Software, Vol. 81, No. 5, pp 772-784, 2008

[5] Laporte, C.Y.; April, A. and Renault, A.; Applying ISO/IEC Software Engineering Standards in Small Settings: Historical Perspectives and Initial Achievements, Proceedings of SPICE Conference, Luxembourg, 2006

[6] Anacleto, A.; von Wangenheim, C.G.; Salviano, C.F.; Savi, R.; Experiences gained from applying ISO/IEC 15504 to small software companies in Brazil, 4th International SPICE Conference on Process Assessment and Improvement, Lisbon, Portugal, April 2004.

[7] ISO/IEC DTR 29110-1, "Software Engineering - Lifecycle Profiles for Very Small Entities (VSE) -- Part 1: VSE profiles Overview”. Geneva: International Organization for Standardization (ISO), 2010.

[8] Laporte, C.Y., Alexandre, S., and O'Connor, R. "A Software Engineering Lifecycle Standard for Very Small Enterprises", R.V.O'Connor et al (Eds) Proceedings of EuroSPI SpringerVerlag, CCIS Vol. 16, pp. 129-141, 2008.

[9] ISO/IEC 12207:2008, Information technology - Software life cycle processes. International Organization for Standardization/International Electrotechnical Commission: Geneva, Switzerland.

[10] ISO/IEC DTR 29110-5, “Software Engineering - Lifecycle Profiles for Very Small Entities (VSE) -- Part 5: Management and Engineering Guide”. Geneva: International Organization for Standardization (ISO), 2010.

[11] ISO/IEC DTR 29110-3, “Software Engineering - Lifecycle Profiles for Very Small Entities (VSE) -- Part 3: Assess Guide”. Geneva: International Organization for Standardization (ISO), 2010.

[12] ISO/IEC DTR 29110-2, “Software Engineering - Lifecycle Profiles for Very Small Entities (VSE) -- Part 2: Framework and Taxonomy”. Geneva: International Organization for Standardization (ISO), 2010.

[13] Deployment Packages repository available from http://profs.logti.etsmtl.ca/claporte/English/VSE/index.html

[14] VSE Pilot Project website public website http://profs.logti.etsmtl.ca/claporte/English/VSE/index.html

[15] VSE Education Special Interest Group http://profs.logti.etsmtl.ca/claporte/English/VSE/VSEEducation.html 